\title{
Impact of Burn Size and Initial Serum Albumin Level on Acute Renal Failure Occurring in Major Burn
}

\author{
Gheun-Ho Kima Kook Hwan Oha J ong Woo Yoon a J a-Ryong Koo ${ }^{a}$ \\ Hyung J ik Kima Dong-Wan Chae ${ }^{a}$ J ung Woo Noha J ong Hyun Kim ${ }^{b}$ \\ Yoon Kyu Park ${ }^{b}$
}

Departments of alnternal Medicine and ${ }^{b}$ General Surgery, Hallym University College of Medicine,

Kangwon Do, South Korea

\section{Key Words}

Acute renal failure - Burn - Albumin - Burn size .

Mortality

\begin{abstract}
Background: Acute renal failure (ARF) is not a rare occurrence in severe burns and is an important complication leading to an increase in mortality. The severity of the burn is largely determined by the burn size, and severe burns are likely to cause enough loss of extracellular fluid and albumin from plasma volume to produce shock and hypoalbuminemia. Hypothesis: We hypothesized that initial serum albumin level may be useful as an indicator of prognosis and severity of injury in burned patients. Methods: The clinical characteristics of 147 adult patients with second- and third-degree burns covering $30 \%$ or more of their body surface area were analyzed retrospectively. Logistic regression was used to estimate the relative risks of ARF and mortality associated with the larger burn size and the lower serum albumin level at admission. Results: Mean burned body surface was $60.0 \pm 21.8 \%$ (range 30-100\%). Twenty-eight
\end{abstract}

(19.0\%) out of 147 patients experienced ARF, defined as a serum creatinine $\geq 2 \mathrm{mg} / \mathrm{dl}$, during the admission. The patients with ARF had larger burn size (79.5 \pm 15.4 vs. $55.3 \pm 20.5 \%, p<0.0001$ ) and lower serum albumin concentration at admission ( $1.92 \pm 0.66$ vs. $2.48 \pm 0.82 \mathrm{~g} / \mathrm{dl}$, $\mathrm{p}<0.0005)$ compared with those without ARF. All patients with ARF expired, whereas $29.4 \%$ (35/119) of the patients without ARF died. The burn size $\geq 65 \%$ was associated with a risk of ARF that was 9.9 times and with a risk of death that was 14.2 times as high as that for the burn size $<65 \%$. The initial serum albumin level $<2.5 \mathrm{~g} / \mathrm{dl}$ was associated with a risk of death that was 2.7 times as high as that for the initial serum albumin level $\geq 2.5 \mathrm{~g} / \mathrm{dl}$. Conclusions: When major burns are complicated by ARF, the mortality rate increases significantly. Burn size is an independent predictor of ARF occurring in major burns. Initially depressed serum albumin level is associated with an increase in mortality in the major burn patients.

\begin{tabular}{ll}
\hline KARGER & ( ) 2003 S. Karger AG, Basel \\
0250-8095/03/0231-0055\$19.50/0 \\
$\begin{array}{l}\text { Fax +4161306 1234 } \\
\begin{array}{l}\text { E-Mail karger@karger.ch } \\
\text { www.karger.com }\end{array}\end{array}$ & $\begin{array}{l}\text { Accessible online at: } \\
\text { www.karger.com/journals/ajn }\end{array}$
\end{tabular}

Gheun-Ho Kim, MD, PhD

Department of Internal Medicine, Hallym University Hangang Sacred Heart Hospital 94-200, Yeongdeungpo-dong, Yeongdeungpo-gu

Seoul 150-020 (South Korea)

Tel. +82 22639 5408, Fax +82 2677 9756, E-Mail gheunho@hanmail.net 


\section{Introduction}

Acute renal failure (ARF) in burns is not a rare occurrence, and the prognosis of burned patients with ARF is known to be grave. The incidence of ARF in burned patients has been reported to vary from 1 to $30 \%$, with the mortality in these patients ranging from 73 to $100 \%$ [1-3]. Despite improved management and the availability of dialytic support, mortality rates in burned patients with ARF have remained above $80 \%[4,5]$. Therefore, whether burn injury is complicated by ARF is very important in patient survival.

Since the severity of the burn is largely determined by the burn size, the burn size would be the limiting factor to survive the thermal injury [6]. It is also conceivable that the occurrence of ARF in burns should depend on the severity of the burns. Holm et al. [7] recently reported a correlation between the burn size and the development of ARF in patients with burns $>10 \%$ body surface area.

Two important factors contributing to the occurrence of ARF in burns are initial hypovolemia and later sepsis $[4,7,8]$. Burns affecting more than $20 \%$ of skin surface are likely to cause enough loss of extracellular fluid and albumin from plasma volume to produce shock and hypoalbuminemia [9]. The ARF occurring in the first few days after the thermal injury is related to intravascular volume depletion [10]. In addition, hypoalbuminemia may result in impaired wound healing [11], predisposing to sepsis. However, it has not been clear whether hypoalbuminemia itself can be used as an independent predictor of ARF or mortality in major burns.

This study was focused on the prognosis of ARF occurring in major burns. 'Major' burns here refer to secondand third-degree burns involving 30\% or more of body surface area. By analyzing the clinical course of ARF occurring in major burn patients, we investigated the impact of burn size and initial serum albumin level on the occurrence of ARF and patient survival in major burns.

\section{Patients and Methods}

The records of 176 acutely burned patients were reviewed. All patients were admitted from January 1, 2000 to December 31, 2000 to the burn intensive care unit at the Hallym University Hangang Sacred Heart Hospital in Seoul, Korea. Of these, the adult ( $>15$ years of age) patients with second- and third-degree burns covering $30 \%$ or more of their body surface area were enrolled. Excluding a few patients with chronic renal failure, 147 patients were subjected to this retrospective analysis.

The following clinical data were collected: age, sex, type of burn, burn size, initial serum albumin concentration (at the time of admis- sion), serial blood urea nitrogen (BUN) and serum creatinine levels, presence or absence of oliguria $(<500 \mathrm{ml} / \mathrm{d})$, duration of hospitalization and factors related to the ARF. Specifically, presence or absence of significant hypotension (mean arterial pressure $<60 \mathrm{~mm} \mathrm{Hg}$ for more than $2 \mathrm{~h}$ ) and sepsis (defined as evidence of infection with a systemic response), requirement of ventilatory support and the use of potentially nephrotoxic agents (aminoglycosides, vancomycin, amphotericin B and nonsteroidal anti-inflammatory drugs) were considered. Information regarding the time of occurrence and causes of $\mathrm{ARF}$, mortality and causes of death were also collected. ARF was defined as an elevation of the serum creatinine level to $2 \mathrm{mg} / \mathrm{dl}$ or more during the admission, considering a possible increase in creatinine release from muscles in burned patients. At admission all burned patients were resuscitated with fluid therapy according to the Parkland's formula [12].

Continuous data were described as means \pm SD. Statistical comparisons between the groups were performed using Mann-Whitney U test, and correlations between variables of interest were analyzed by linear regression. $p<0.05$ were considered as indicative of statistical significance.

Categorical data were analyzed using contingency tables and $\chi^{2}$ test. Burn size was analyzed as both continuous and categorical $(<65$ and $\geq 65 \%$ ) predictors of the risk of ARF and mortality. Initial serum albumin concentration was also analyzed as both continuous and categorical $(<2.5$ and $\geq 2.5 \mathrm{~g} / \mathrm{dl})$ predictors of the risk of ARF and mortality. The cutoff levels dividing the patients into two groups of burn size or initial serum albumin were determined based on the frequency distribution data. Logistic regression was used to model odds ratios and $95 \%$ confidence intervals as measures of the association between predictors and outcomes (SPSS for Windows; SPSS Inc., Chicago, Ill., USA).

\section{Results}

\section{General Characteristics of the Patients}

A total of 147 patients were entered into the study. There were 106 men and 41 women with a mean age of $43.2 \pm 14.1$ years (range 16-87). Mean second- or thirddegree burned body surface, as evaluated upon arrival, was $60.0 \pm 21.8 \%$ (range $30-100 \%$ ) of the total body surface area. One hundred twenty-seven patients had sustained flame burns, 10 were scalds, 8 electric burns and 2 chemical burns.

Twenty-eight out of 147 patients experienced ARF, defined as a serum creatinine $\geq 2 \mathrm{mg} / \mathrm{dl}$, during the admission. Thus, the incidence of ARF in our major burn patients was $19.0 \%$. Sixty-three out of 147 patients died, corresponding to the total mortality rate of $42.9 \%$. Major causes of death were septic shock, acute respiratory distress syndrome and burn shock.

\section{Characteristics of the Patients with ARF}

ARF occurred a mean of 6.8 days (range 1-36) after admission. At the time of ARF, 14 patients (50\%) were 
oliguric. During the admission, BUN reached $55.7 \pm$ $29.2 \mathrm{mg} / \mathrm{dl}$ and serum creatinine $4.08 \pm 3.04 \mathrm{mg} / \mathrm{dl}$. Oliguric ARF patients had higher peak BUN level compared with nonoliguric ARF patients $(65.7 \pm 24.8$ vs. $45.7 \pm$ $30.7 \mathrm{mg} / \mathrm{dl}, \mathrm{p}<0.05)$, but peak creatinine level was not different between the two groups $(4.36 \pm 3.07$ vs. $3.79 \pm$ $3.09 \mathrm{mg} / \mathrm{dl}$ ). The major contributors preceding the ARF were usually multifactorial: significant hypotension (burn shock), rhabdomyolysis, sepsis and use of aminoglycosides. Whereas the ARF associated with significant hypotension or rhabdomyolysis occurred during the first week of admission, the ARF associated with sepsis or use of aminoglycosides occurred thereafter.

Clinical parameters at admission were compared between the patients with ARF and those without ARF (table 1). Age and sex distribution had no differences between the two groups. Most of our patients had flame burns and we could not find any difference according to the burn types. The patients with ARF had larger burn size compared with those without ARF (79.5 \pm 15.4 vs. $55.3 \pm 20.5 \%, \mathrm{p}<0.0001)$. The patients with ARF had lower serum albumin concentration at admission compared with those without ARF $(1.92 \pm 0.66$ vs. $2.48 \pm$ $0.82 \mathrm{~g} / \mathrm{dl}, \mathrm{p}<0.0005)$.

Table 2 shows comparisons of the parameters during the admission between the two groups. As expected, episodes of significant hypotension, sepsis and requirement of ventilatory support were more frequent in the patients with ARF than in those without ARF. Notably, all the patients with ARF expired whereas 29.4\% (35/119) of the patients without ARF died. Shorter duration of hospitalization in the patients with ARF $(11.3 \pm 7.9$ vs. $64.4 \pm$ 63.3 days, $\mathrm{p}<0.0001$ ) seemed to be related with this higher mortality. In only 3 patients, renal replacement therapy using intermittent hemodialysis or continuous venovenous hemofiltration was performed. The indication for renal replacement therapy in these patients was progressive azotemia accompanying pulmonary edema. Patient survival was not affected by the application of renal replacement therapy.

\section{Risks of ARF and Death}

Figure 1 shows a clear tendency that ARF occurred more frequently in the patients with a larger burn size and those with a lower initial serum albumin level. We evaluated the relative risks of $\mathrm{ARF}$ associated with age $\geq 45$ years, male sex, burn size $\geq 65 \%$ and initial serum albumin $<2.5 \mathrm{~g} / \mathrm{dl}$ (table 3). The incidence of ARF was not associated with age or sex. The burn size $\geq 65 \%$ body surface area was associated with a risk of ARF that was 9.9
Table 1. Comparisons of parameters at admission between patients with and without ARF

\begin{tabular}{lll}
\hline & $\begin{array}{l}\text { With ARF } \\
(\mathrm{n}=28)\end{array}$ & $\begin{array}{l}\text { Without ARF } \\
(\mathrm{n}=119)\end{array}$ \\
\hline Age, years & $41.9 \pm 13.2$ & $43.5 \pm 14.4$ \\
Sex ratio, M:F & $22: 6$ & $84: 35$ \\
Burn type & & \\
$\quad$ Flame & 25 & 102 \\
$\quad$ Scald & 1 & 9 \\
$\quad$ Electric & 1 & 7 \\
$\quad$ Chemical & 1 & 1 \\
Burn size, \% & $79.5 \pm 15.4$ & $55.3 \pm 20.5^{* *}$ \\
Serum albumin, g/dl & $1.92 \pm 0.66$ & $2.48 \pm 0.82^{*}$ \\
\hline
\end{tabular}

Continuous variables are presented as mean $\pm \mathrm{SD} . * \mathrm{p}<0.0005$ ** $\mathrm{p}<0.0001$.

Table 2. Comparisons of parameters during the admission between patients with and without ARF

\begin{tabular}{lll}
\hline & $\begin{array}{l}\text { With ARF } \\
(\mathrm{n}=28)\end{array}$ & $\begin{array}{l}\text { Without ARF } \\
(\mathrm{n}=119)\end{array}$ \\
\hline Significant hypotension & 22 & $31^{* *}$ \\
Sepsis & 27 & $75^{*}$ \\
Septicemia & 6 & 29 \\
Requirement of ventilatory support & 27 & $40^{* *}$ \\
Peak BUN, mg/dl & $55.7 \pm 29.2$ & $17.2 \pm 9.09^{* *}$ \\
Peak serum creatinine, mg/dl & $4.08 \pm 3.04$ & $1.01 \pm 0.31^{* *}$ \\
Duration of hospitalization, days & $11.3 \pm 7.9$ & $64.4 \pm 63.3^{* *}$ \\
Death & 28 & $35^{* *}$ \\
\hline
\end{tabular}

Continuous variables are presented as mean $\pm \mathrm{SD} .{ }^{*} \mathrm{p}<0.001$; $* * \mathrm{p}<0.0001$

times as high as that for the burn size $<65 \%$ in multivariate analysis. The initial serum albumin level $<2.5 \mathrm{~g} / \mathrm{dl}$ was associated with increased risk of ARF in univariate analysis but not significant in multivariate analysis. Thus, the initial serum albumin level did not seem to be an independent predictor of ARF, as reflected by its correlation with the burn size ( $p<0.0001$, fig. 2$)$.

Figure 3 shows a clear tendency of increasing mortality in the patients with a larger burn size and those with a lower initial serum albumin level. We estimated the relative risks of death associated with age $\geq 45$ years, male sex, burn size $\geq 65 \%$ and initial serum albumin $<2.5 \mathrm{~g} / \mathrm{dl}$ (table 4). The risk of death was not affected by age or sex. The burn size $\geq 65 \%$ body surface area was associated 


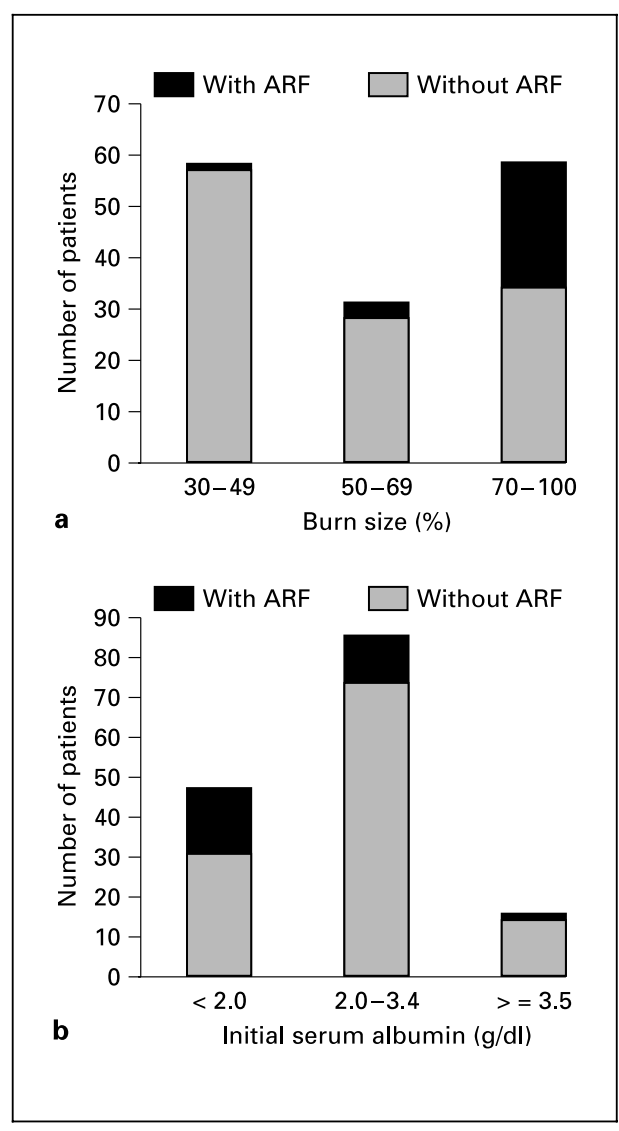

Fig. 1. Incidence of $A R F$ according to burn size (a) and serum albumin concentration (b) at admission.

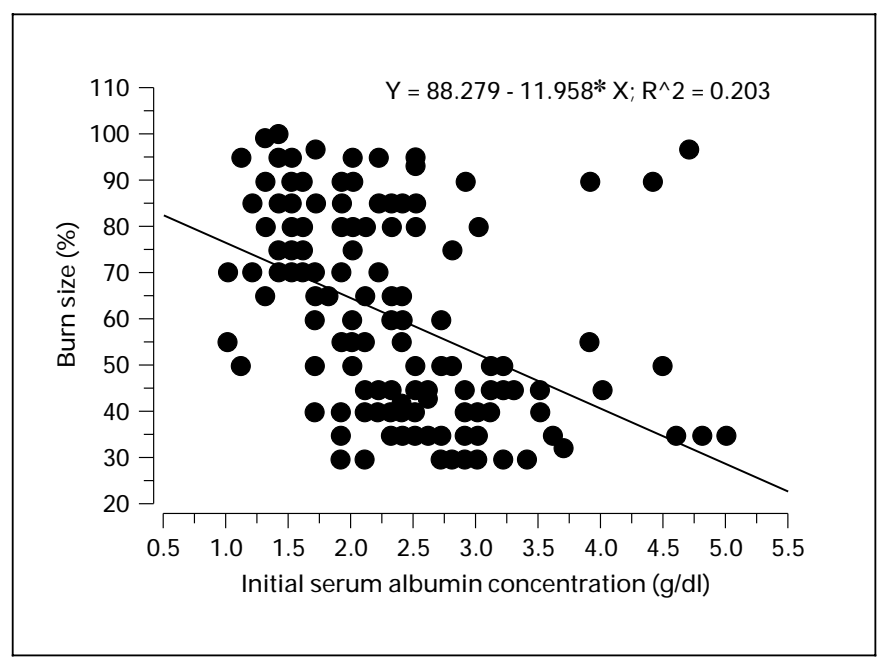

Fig. 2. Correlation between burn size and serum albumin concentration at admission.

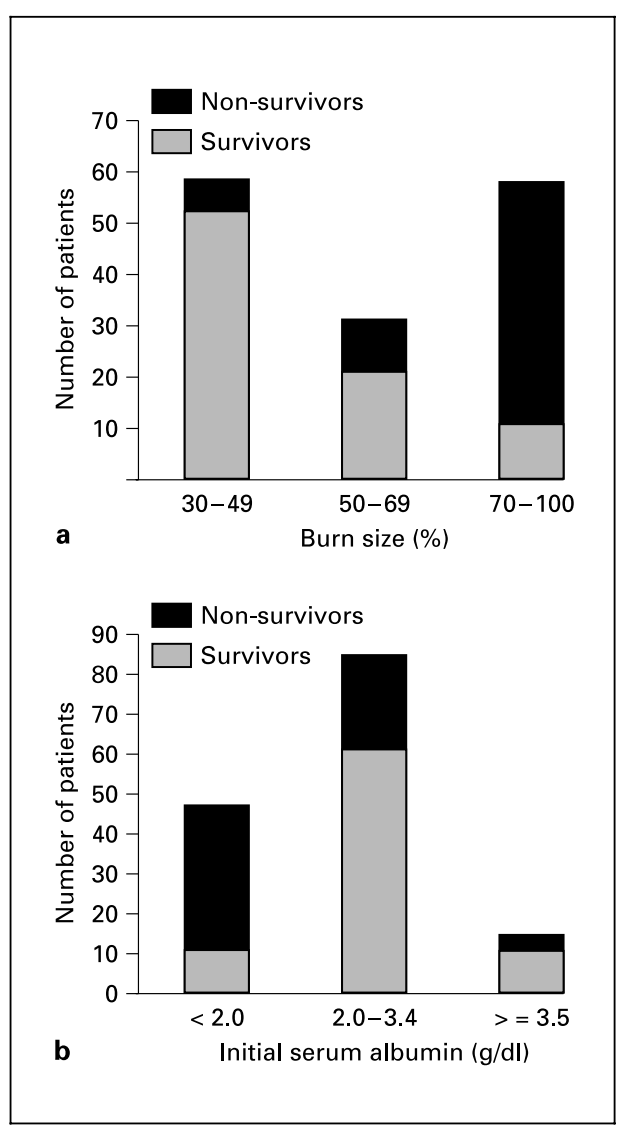

Fig. 3. Mortality according to burn size (a) and serum albumin concentration (b) at admission.

with a risk of death that was 14.2 times as high as that for the burn size $<65 \%$ in multivariate analysis. The initial serum albumin level $<2.5 \mathrm{~g} / \mathrm{dl}$ was also associated with a risk of death that was 2.7 times as high as that for the initial serum albumin level $\geq 2.5 \mathrm{~g} / \mathrm{dl}$ in multivariate analysis.

\section{Discussion}

In this retrospective study of 147 patients seen over a 1 -year period at single burn unit, we showed that about one-fifth of the major burn ( $\geq 30 \%$ body surface area) patients is complicated by ARF (serum creatinine $\geq 2.0 \mathrm{mg} / \mathrm{dl}$ ) and that the combination of major burn and ARF is invariably fatal. Considering most of our patients with ARF were septic and in the need of ventilatory support, the presence of multiple organ failure should be the main reason why they could not survive. 
Table 3. Odds ratios for ARF in major burns associated with the parameters at admission

\begin{tabular}{lccllll}
\hline & \multicolumn{2}{c}{ Univariate analysis } & & \multicolumn{2}{c}{ Multivariate analysis } \\
\cline { 2 - 3 } & odds ratio & $95 \% \mathrm{CI}$ & & & odds ratio & $95 \% \mathrm{CI}$ \\
\hline Age $\geq 45$ years & 0.84 & $0.37-1.94$ & & 0.94 & $0.37-2.35$ \\
Male sex & 1.53 & $0.57-4.09$ & & 1.88 & $0.64-5.50$ \\
Burn size $\geq 65 \%$ & 11.9 & $3.85-36.5$ & & 9.87 & $2.86-34.1$ \\
Serum albumin $<2.5 \mathrm{~g} / \mathrm{dl}$ & 4.13 & $1.56-10.9$ & & 1.59 & $0.51-4.99$ \\
\hline
\end{tabular}

\begin{tabular}{lcclccc}
\hline & \multicolumn{2}{c}{ Univariate analysis } & & \multicolumn{2}{c}{ Multivariate analysis } \\
\cline { 2 - 3 } & odds ratio & $95 \% \mathrm{CI}$ & & & odds ratio & $95 \% \mathrm{CI}$ \\
\hline Age $\geq 45$ years & 1.23 & $0.64-2.37$ & & 1.72 & $0.71-4.15$ \\
Male sex & 0.82 & $0.40-1.70$ & & 1.02 & $0.40-2.63$ \\
Burn size $\geq 65 \%$ & 19.2 & $8.32-44.4$ & & 14.2 & $5.71-35.2$ \\
Serum albumin $<2.5 \mathrm{~g} / \mathrm{dl}$ & 6.64 & $3.15-14.0$ & & 2.65 & $1.06-6.64$ \\
\hline
\end{tabular}

Table 4. Odds ratios for patient survival in major burn associated with the parameters at admission burned patients. Burn injury to skin initiates an intense inflammatory response and release of vasoactive agents, increasing capillary permeability to fluid, albumin and even larger proteins at the burn site [16]. This process reaches its peak in 12-24 h. Albumin has clearly been shown to leak from the intravascular space during at least the first $6-18 \mathrm{~h}$ after injury $[17,18]$. Besides, examination of the livers of burned animals reveals that the messenger RNA for albumin is decreased in response to injury [19, 20], a response that is associated with the increase in acute phase reactants. After burn shock, therefore, serum albumin levels would continue to decrease because of decreased production and ongoing losses through the wound.

Depressed serum albumin levels at admission have been found to be predictors of higher complication rates for patients with varying clinical problems [11]. In burned patients, the degree of burn involvement may be reflected by the serum albumin concentration at admission. In this context, we showed a significant correlation between burn size and serum albumin level at admission (fig. 2). In addition, depressed serum albumin level at admission was associated with increased risk of ARF and death in univariate analysis. According to the multivariate analysis, however, the initially depressed serum albumin level was not an independent predictor of ARF but an independent predictor of death in the major burn patients. It is probable that serum albumin level at admission may be determined by not only the degree of thermal injury but 
also premorbid conditions. Therefore, patient survival might have been affected by premorbid conditions.

In this study, only a few of the patients were dialyzed. Because of the small number of the dialyzed patients, we could not conclude whether renal replacement therapy brought about any benefit in patient survival. Although only 6 patients out of 28 with ARF had their serum creatinine $>5 \mathrm{mg} / \mathrm{dl}$, we cannot but admit that burn surgeons in our unit were not very much aware of the need of early dialysis and that the nephrologists involved were not very persuasive in applying renal replacement therapy to those multiorgan failure patients. The prognosis might have been improved with early aggressive application of renal replacement therapy $[7,8,21]$.
We conclude that major burns, if complicated by ARF, could be fatal. The risks of ARF and mortality may be predetermined at admission. We cannot be too eager in early fluid resuscitation in major burns. Further studies are required to verify whether patient survival can be improved with early aggressive application of renal replacement therapy in major burn patients.

\section{Acknowledgments}

The authors gratefully acknowledge the advice of Drs. Dong-Kun Kim and Goo-Yeong Cho.

\section{References}

1 Sawada Y, Momma S, Takamizawa A, Nishida S: Survival from acute renal failure after severe burns. Burns 1984;11:143-147.

2 Schiavon M, Di Landro D, Baldo M, De Silvestro G, Chiarelli A: A study of renal damage in seriously burned patients. Burns 1988;14:107112.

3 Stott RB, Cameron JS, Ogg CS, Bewick M Why the persistently high mortality in acute renal failure. Lancet 1972;ii:75-79.

4 Davies MP, Evans J, McGonigle RJ: The dialysis debate: Acute renal failure in burns patients. Burns 1994;20:71-73.

5 Leblanc M, Thibeault Y, Querin S: Continuous haemofiltration and haemodiafiltration for acute renal failure in severely burned patients. Burns 1997;23:160-165.

6 Periti P, Donati L: Survival and therapy of burn patients at the threshold of the twentyfirst century: A review. J Chemother 1995; 7 : 475-502.

7 Holm C, Horbrand F, von Donnersmarck GH, Muhlbauer W: Acute renal failure in severely burned patients. Burns 1999;25:171-178.

8 Chrysopoulo MT, Jeschke MG, Dziewulski P, Barrow RE, Herndon DN: Acute renal dysfunction in severely burned adults. J Trauma 1999;46:141-144.
9 Holliday MA: Extracellular fluid and its proteins: Dehydration, shock and recovery. Pediatr Nephrol 1999; 13:989-995.

10 Boswick JA Jr, Thompson JD, Kershner CJ: Critical care of the burned patient. Anesthesiology 1977;47:164-170.

11 Doweiko JP, Nompleggi DJ: The role of albumin in human physiology and pathophysiology. III. Albumin and disease states. J Parenter Enteral Nutr 1991;15:476-483.

12 Haupt MT, Kaufman BS, Carlson RW: Fluid resuscitation in patients with increased vascular permeability. Crit Care Clin 1992;8:341353.

13 Muller MJ, Pegg SP, Rule MR: Determinants of death following burn injury. Br J Surg 2001; 88:583-587.

14 Smith DL, Cairns BA, Ramadan F, Dalston JS, Fakhry SM, Rutledge R, Meyer AA, Peterson HD: Effect of inhalation injury, burn size and age on mortality: A study of 1,447 consecutive burn patients. J Trauma 1994;37:655-659.

15 Ryan CM, Schoenfeld DA, Thorpe WP, Sheridan RL, Cassem EH, Tompkins RG: Objective estimates of the probability of death from burn injuries. N Engl J Med 1998;338:362-366.
16 Arturson G: Pathophysiology of the burn wound and pharmacological treatment. The Rudi Hermans Lecture, 1995. Burns 1996;22: 255-274.

17 Birke G, Liljedahl SO, Plantin LO, Reizenstein P: Studies on burns. IX. The distribution and losses through the wound of ${ }^{131}$ I-albumin measured by whole-body counting. Acta Chir Scand 1968;134:27-36.

18 Brouhard BH, Carvajal HF, Linares HA: Burn edema and protein leakage in the rat. I. Relationship to time of injury. Microvasc Res 1978; 15:221-228.

19 Dickson PW, Bannister D, Schreiber G: Minor burns lead to major changes in synthesis rates of plasma proteins in the liver. J Trauma 1987; 27:283-286.

20 Sevaljevic L, Ivanovic-Matic S, Petrovic M, Glibetic M, Pantelic D, Poznanovic G: Regulation of plasma acute-phase protein and albumin levels in the liver of scalded rats. Biochem J 1989;258:663-668.

21 Hubsher J, Olshan AR, Schwartz AB, Zoranski B, DeClement F, Bendlin A, Hensell D, Brezin JH, Krevolin LE, Chinitz JL: Continuous arteriovenous hemofiltration for the treatment of anasarca and acute renal failure in severely burned patients. ASAIO Trans 1986;32:401404. 